\title{
FAILURE BEHAVIOUR OF PRELOADED API LINE PIPE THREADED CONNECTIONS
}

\author{
J. Seys, K. Roeygens, J. Van Wittenberghe, T. Galle, P. De Baets and W. De Waele \\ Ghent University, Laboratory Soete, Belgium
}

\begin{abstract}
This paper reports on numerical and experimental work concerning the fatigue behaviour and sealing capacity of threaded pipe connections (1" API Line Pipe). Numerical simulations are performed using Abaqus ${ }^{\circledR}$ in combination with ThreadGen ${ }^{\odot}$. The fatigue life of a thick-walled standard coupling is determined using a four-point bending test. The corresponding S-N curve is compared to results of previous work on thin-walled specimens. It can be concluded that the standard thick-walled connection has a higher fatigue life than thin-walled ones. In future work, the prediction of fatigue life using established multi-axial criteria will be evaluated. Further, the sealing capacity of several couplings will be investigated by submitting them to different combinations of internal pressure and axial force. Hereto, a specific test setup is designed. The results will then be presented as a test load envelope [1].
\end{abstract}

Keywords - Threaded connections, API, fatigue, four-point bending, sealing limit, test load envelope, finite element analysis

\section{INTRODUCTION}

Threaded pipe couplings for joining tubular pipes have been used extensively in applications such as down hole casing, drill pipe strings and TLP tendons. An API line pipe connection consists of a male member, also known as the pin, which is made up into a female part, also known as the box. They have the advantage that they can be easily coupled and uncoupled. In offshore applications, connections can be subjected to cyclic loads, e.g. when drilling deviated wells or due to movement of oil platforms. In case of risers and drill pipes, fatigue is one of the most important failure modes. Since the highest stress concentration occurs at the root of the last engaged thread (LET, Figure 1) of the pin, fatigue cracks commonly initiate at this location. However, the fundamental knowledge on the actual crack initiation and propagation is still inadequate. To that purpose, studies of the fracture surface, based on the beach marking technique, will be carried out. Apart from fatigue, the thread sealing performance of thin- and thickwalled connections will also be investigated.

Threaded connections can be divided in two main categories, standard connections and premium connections. Standard API line pipe, casing and tubing connections are defined by the API 5B and API 5L specifications [2, 3]. Premium connections are designed to have a better fatigue strength and/or optimised sealing properties [4-7].

In this study, fatigue performance is experimentally evaluated using a four-point bending fatigue setup. The number of cycles which the coupling can sustain at a specified stress ratio and amplitude will be determined to develop S-N curves. Numerical simulations are carried out using the commercial software package Abaqus $6.10^{\circledR}$. The input and output processing are automated by ThreadGen ${ }^{\odot}$, software developed at Ghent University. Results will be compared with previous work on thin-walled (pin thickness = $3,4 \mathrm{~mm}$ ) standard and modified connections [4, 5]. An objective of this research is to determine the influence of the pin stiffness by carrying out research on thick-walled (pin thickness $=4,5 \mathrm{~mm}$ ) connections.

In future work, sealing performance will be examined by submitting the connection to load envelope tests as defined in ISO 13679 [1]. Test procedures for connection application level 1 (CAL 1) expose the connection to cyclical loads, including internal and external (water) pressure, and axial tension and compression. Failure occurs when the connection experiences leakage or a loss of structural integrity.

The ultimate goal of this research is to give guidance on coupling designs with an optimum combination of sealing capacity and resistance to fatigue failure. 


\section{FATIGUE BEHAVIOUR}

\section{1 $\quad$ Finite element modelling}

To simulate the structural behaviour of threaded connections, a 2D axisymmetric model is used [8]. The model of the standardized API line pipe connection is shown in Figure 1(a). The connection has a nominal size of 1 " according to the API 5B specifications. Other important properties for the thick-walled pin are listed in Figure 1(b).

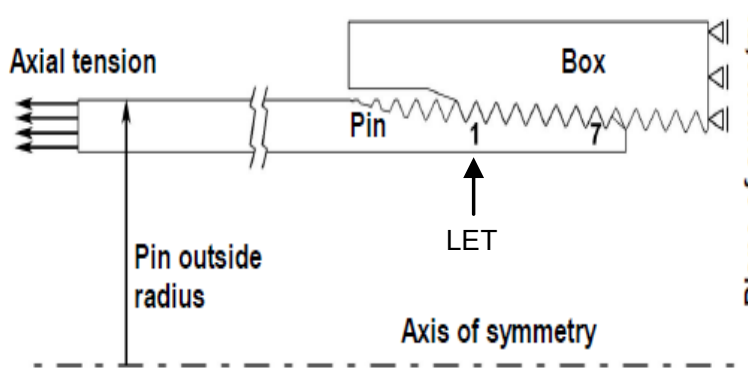

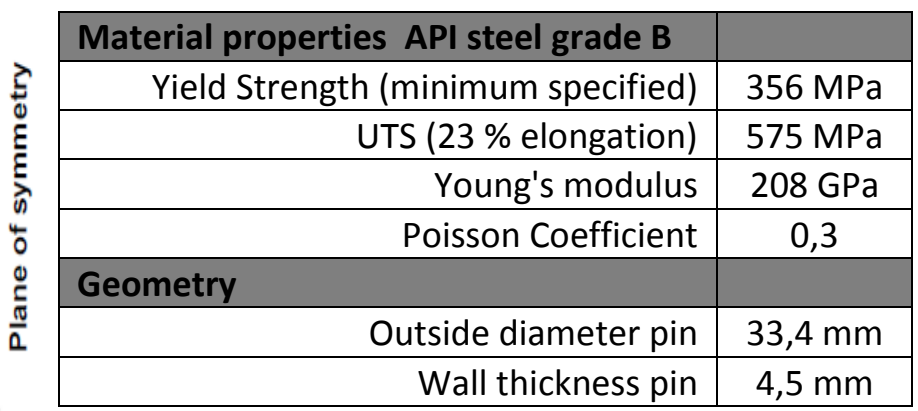

Figure 1: a) 2D axisymmetric model of an API Line Pipe coupling, b) material properties and geometry

The analyses are carried out using the software ABAQUS ${ }^{\circledR} 6.10$ and ThreadGen [9]. A fine mesh was seeded along the pin thread roots, since it is known that those locations are most susceptible for fatigue crack initiation. Hereto, four node bilinear axisymmetric quadrilateral elements with reduced integration (CAX4R) are used.

The finite element analysis consists of two consecutive load steps:

- To maintain a sealed and secured connection, the tapered members are preloaded with a make-up torque. For a thick-walled pin this corresponds with 2 make-up turns on top of a hand-tight situation. This is modelled by an initial overlap of the threads of pin and box.

- During the second step, an additional axial tensile stress up to $150 \mathrm{MPa}$ is applied. The highest stress concentration appears, as already mentioned, at the root of the LET of the pin. This is mainly caused by an uneven distribution of the axial forces over the engaged threads.

The LET is the most common place where fatigue cracks initiate. When trying to improve the fatigue life of a threaded connection, one should try to obtain a more uniform load distribution and hence have a lower load and stress intensity factor at the LET. In previous research, this was attempted by a stiffness reduction of the box. However, it was found that it is not possible to simply state that a more uniform load distribution leads to longer fatigue life. Indeed, experiments on couplings with a reduced box wall thickness of $2 \mathrm{~mm}$ did not reveal a longer fatigue life despite a more uniform load distribution (Figure 2) [4].

The load distribution of a standard thick-walled coupling is also included in Figure 2. The relative thread load reaches its maximum at the LET, which is the same as for a thin-walled coupling with a $-5 \mathrm{~mm}$ recess, but has a less uniform distribution than the coupling with a reduced box wall thickness of $2 \mathrm{~mm}$. This result does not allow us to make correct fatigue life predictions, since experiments on standard thick-walled coupling resulted in the best fatigue life so far (see 2.2 Fatigue experiments). 


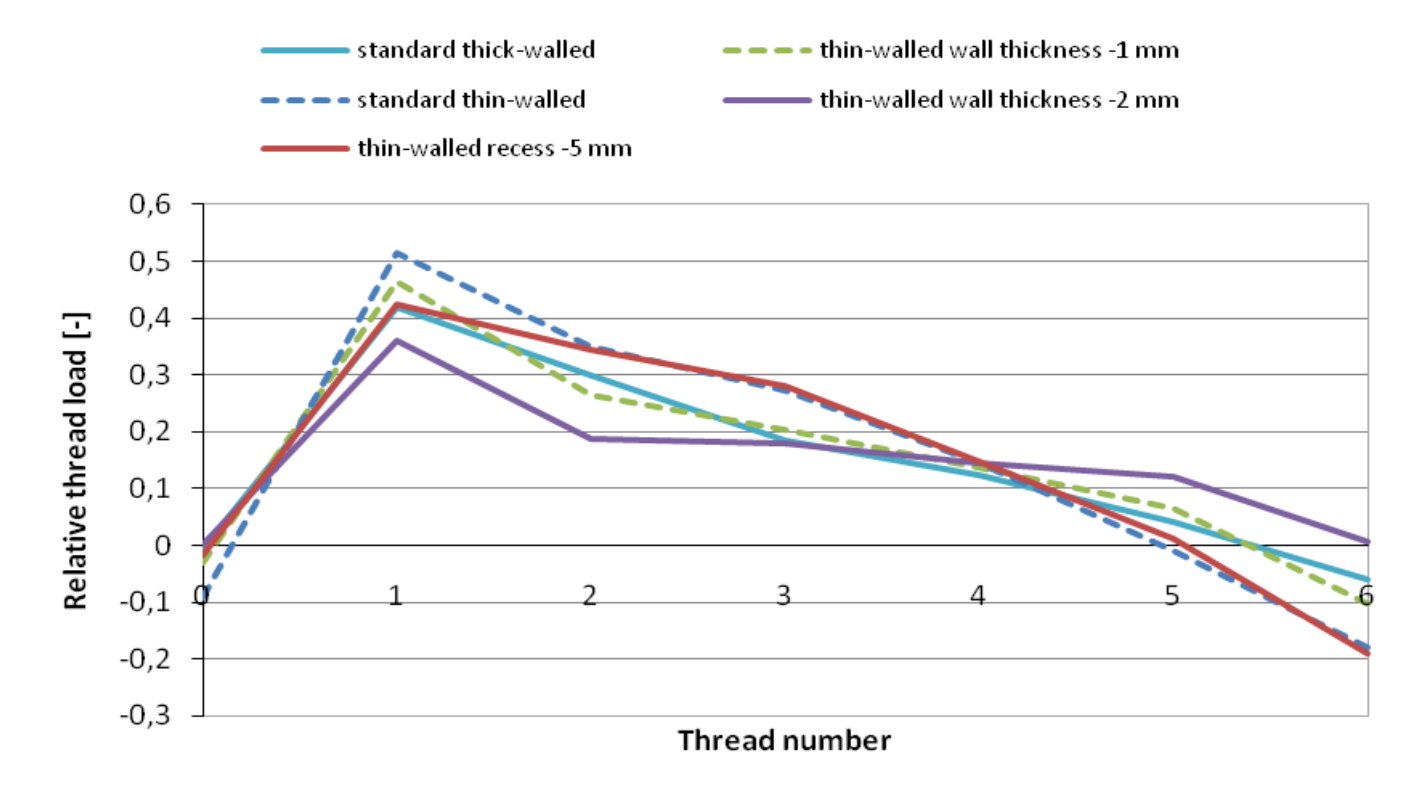

Figure 2: Thread load distribution (make-up and axial tension of $150 \mathrm{MPa}$ ) of standard and premium connections

It is well-known that stress multi-axiality plays an important role in fatigue life evaluation. For this reason, both the axial stress distribution and the tri-axiality (defined as in equation (1) [10]), are investigated.

$$
\mathrm{R}_{\mathrm{v}}=\frac{2}{3}(1+\mathrm{v})+3(1-2 \mathrm{v}) \frac{\sigma_{\mathrm{h}}^{2}}{\sigma_{\mathrm{vm}}^{2}}
$$

In this equation $\sigma_{h}$ is the hydrostatic pressure, $\sigma_{v m}$ the von Mises equivalent stress and $v$ the Poisson's ratio. A high tri-axiality has a positive influence on the fatigue resistance. Hydrostatic pressure has no effect on the occurrence of yielding. The greater the hydrostatic pressure compared to the von Mises stress, the smaller the deviatoric stress components that determine yielding behaviour. The axial stress and hydrostatic pressure of a thick walled standard connection are shown in Figure 3.

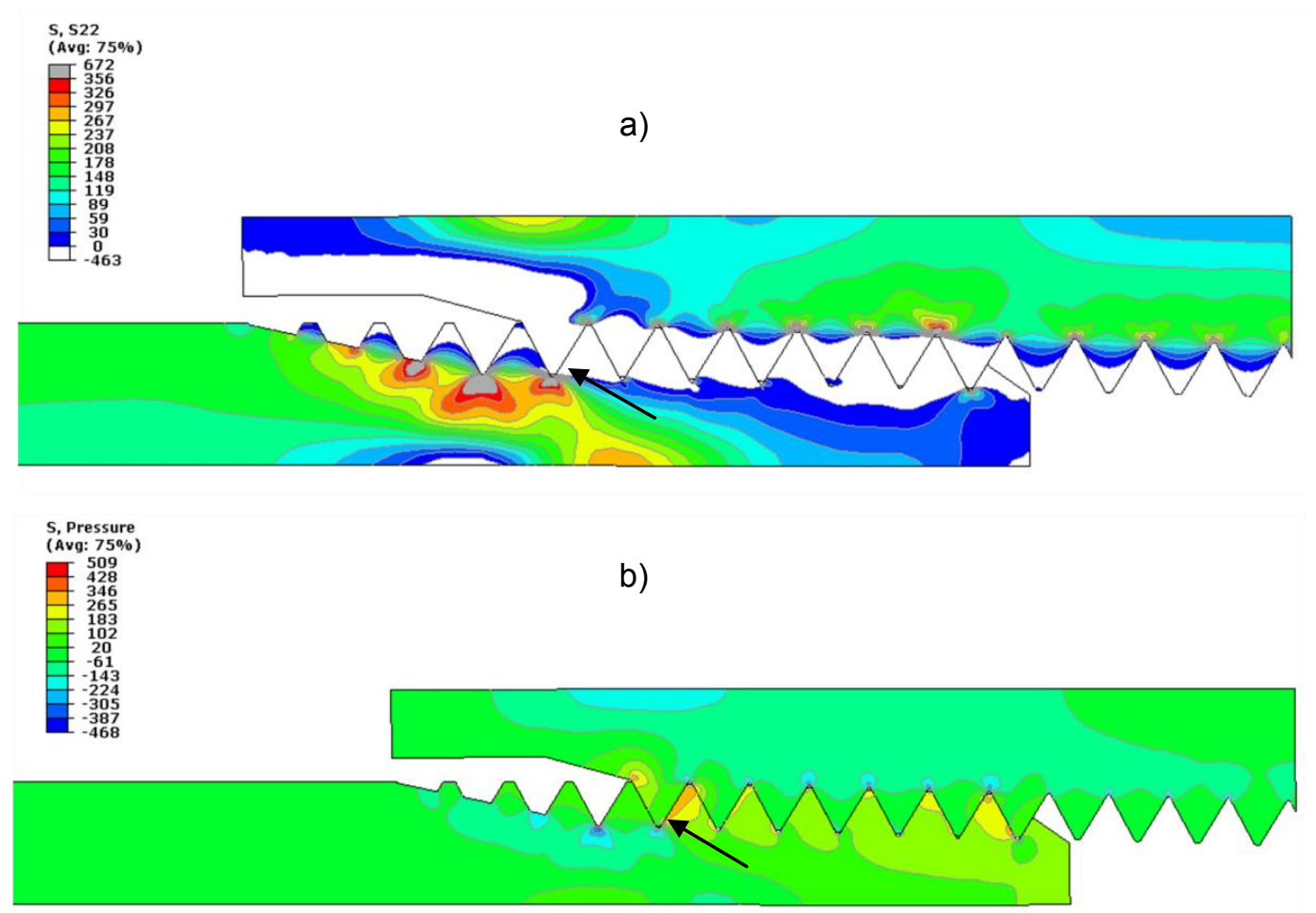

Figure 3: Stresses in a standard thick walled coupling subjected to make-up and axial tension of $150 \mathrm{MPa}$ a) axial stress, b) hydrostatic pressure 
Unlike Figure 3(a), where the tensile stresses are positive, in Figure 3(b) the compressive stresses are positive. It can be seen that at the LET, due to the high stress concentration, there is a high axial stress exceeding by far the minimum specified yield strength of $356 \mathrm{MPa}$. There is also a high hydrostatic pressure (negative so tensile stress) which gives in equation (1) a high value for the tri-axiality.

However, more research is necessary to provide a correlation with fatigue life. To this end, the multi-axial fatigue criterion (equation(2)) demonstrated in [6] will be used:

$$
N_{f}=\frac{\Delta \sigma_{e q}^{-(\beta+m)} R_{V}^{-\beta / 2}}{A(\beta+m+1)}
$$

In this equation, $A$ and $\beta$ are damage parameters and material constants, $m$ is the strain hardening exponent of the coupling material $(m=9.52), \Delta \sigma_{e q}$ is the difference between the maximum and minimum von Mises equivalent stress during a load cycle and $R_{V}$ is the tri-axiality function as given in equation (1).

Previous research [6] showed that $\beta \quad 0$ and $(\beta+m)>0$. As a result, high tri-axiality in combination with low von Mises stress amplitude results in high fatigue life prediction.

In Table 1, the values for different stresses at the root of the LET are listed. These have been determined by calculating their mean value along two fixed paths at the root of the LET (see Figure 4 \&5). The different connections are organized by increasing fatigue life.

The path along the edge gives hopeful results. The standard thick-walled coupling shows a high tri-axiality in combination with a low von Mises stress (so also a low $\Delta \sigma_{e q}$ ). The thin-walled coupling with a reduced box wall thickness of $2 \mathrm{~mm}$ has a high tri-axiality, but experiences a high von Mises stress. So, even though no real fatigue life predictions are made, a trend arises between the multi-axial fatigue criterion and fatigue life. An additional improvement to determine stress values at the root of the LET might be to integrate over a well chosen area instead of integrating along a line path.

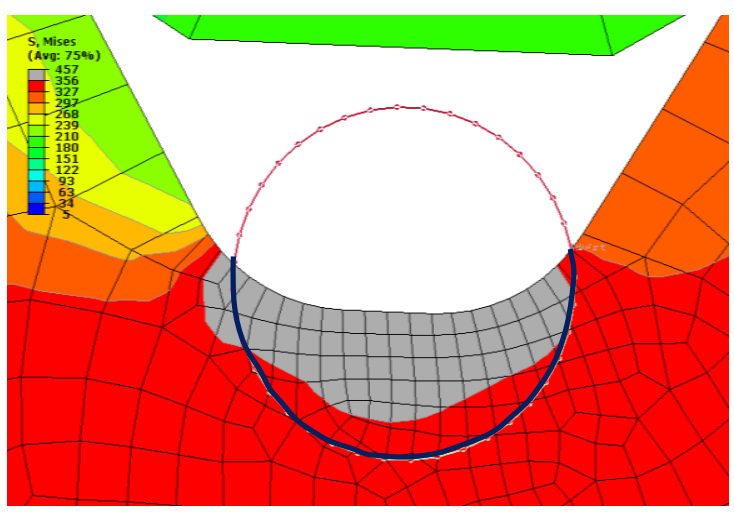

Figure 4: Circular path

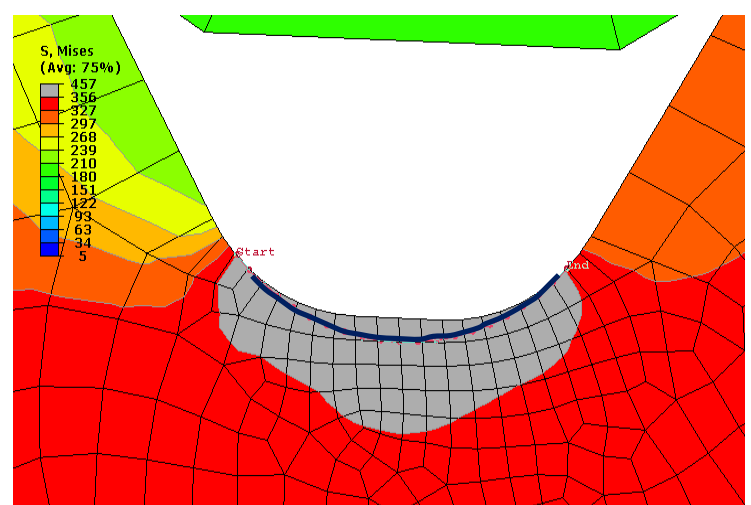

Figure 5: Path along edge

\begin{tabular}{|l|c|c|c|c|c|c|}
\hline & \multicolumn{2}{|c|}{ Axial stresses } & Von Mises stresses & \multicolumn{2}{c|}{ Tri-axiality } \\
\hline & circle & edge & circle & edge & circle & edge \\
\hline Standard thin-walled & 476 & 446 & 390 & 440 & 0,56 & 0,45 \\
\hline Thin-walled WT-2 & 541 & 451 & 390 & 453 & 1,00 & 0,48 \\
\hline Thin-walled WT-1 & 447 & 420 & 363 & 417 & 0,57 & 0,44 \\
\hline Thin-walled recess-5 & 473 & 438 & 389 & 437 & 0,58 & 0,45 \\
\hline Standard thick-walled & 443 & 411 & 350 & 362 & 0,69 & 0,50 \\
\hline
\end{tabular}

Table 1 : Stresses (MPa) and tri-axiality (-) at the root of the LET 


\section{$2.2 \quad$ Fatigue experiments}

Fatigue performance is experimentally evaluated using a four-point bending setup (Figure 6), which ensures equal loads at both coupling ends. Tests are carried out under load control with a load ratio $R=0,1$ and at a testing frequency of $15 \mathrm{~Hz}$. When a fatigue crack grows through the wall thickness of a pipe, the applied internal pressure of 3.5 bar drops and the test is stopped.

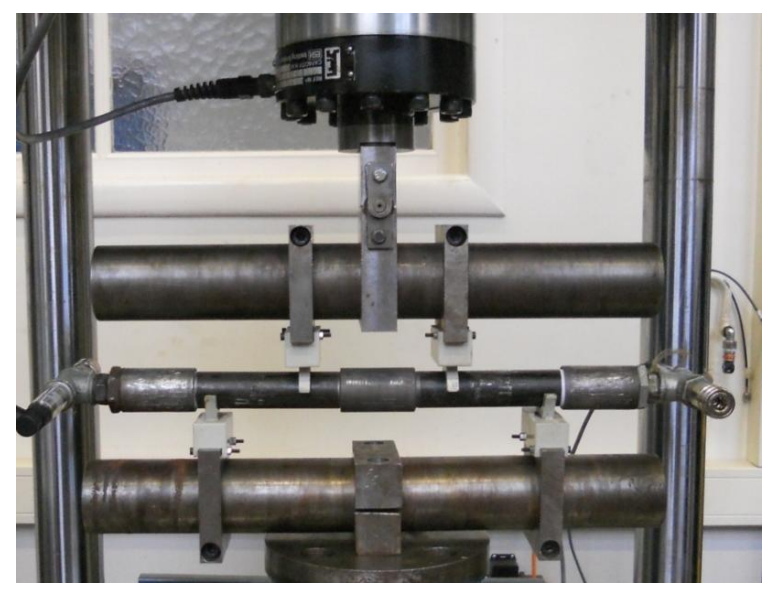

Figure 6: Four-point bending fatigue setup

Twelve tests on 1" thick-walled API line pipe couplings have been carried out. One specimen, loaded with a stress amplitude of $12,5 \%$ of the minimum specified yield strength, did not fail after 3 million cycles. The corresponding S-N curves are shown in Figure 7. The mean S-N curve is the best least-squares fit of all data points (equation 3 ). The design curve is equal to the mean curve minus two standard deviations. A fatigue limit of 2 million cycles is put forward.

$$
S_{a}=247,35 \cdot N^{-0,202}
$$

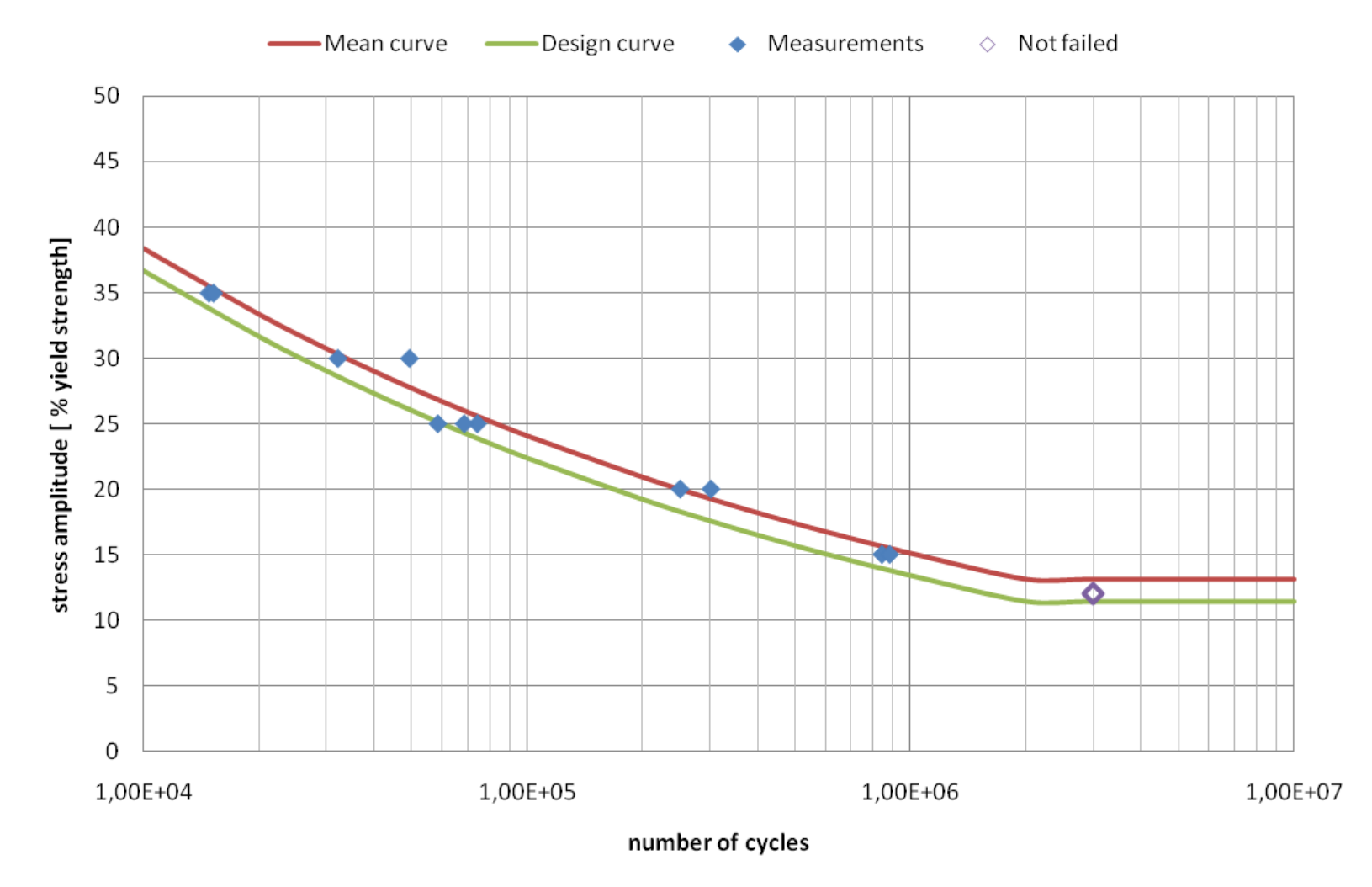

Figure 7: Experimentally determined S-N curves for standard 1" thick-walled API Line Pipe couplings. 
In the figure below, the mean curve is compared with results for thin-walled standard and premium connections [4,5]. The thick-walled connection shows an overall higher fatigue life. A pin with higher stiffness results in a better distribution of stresses.

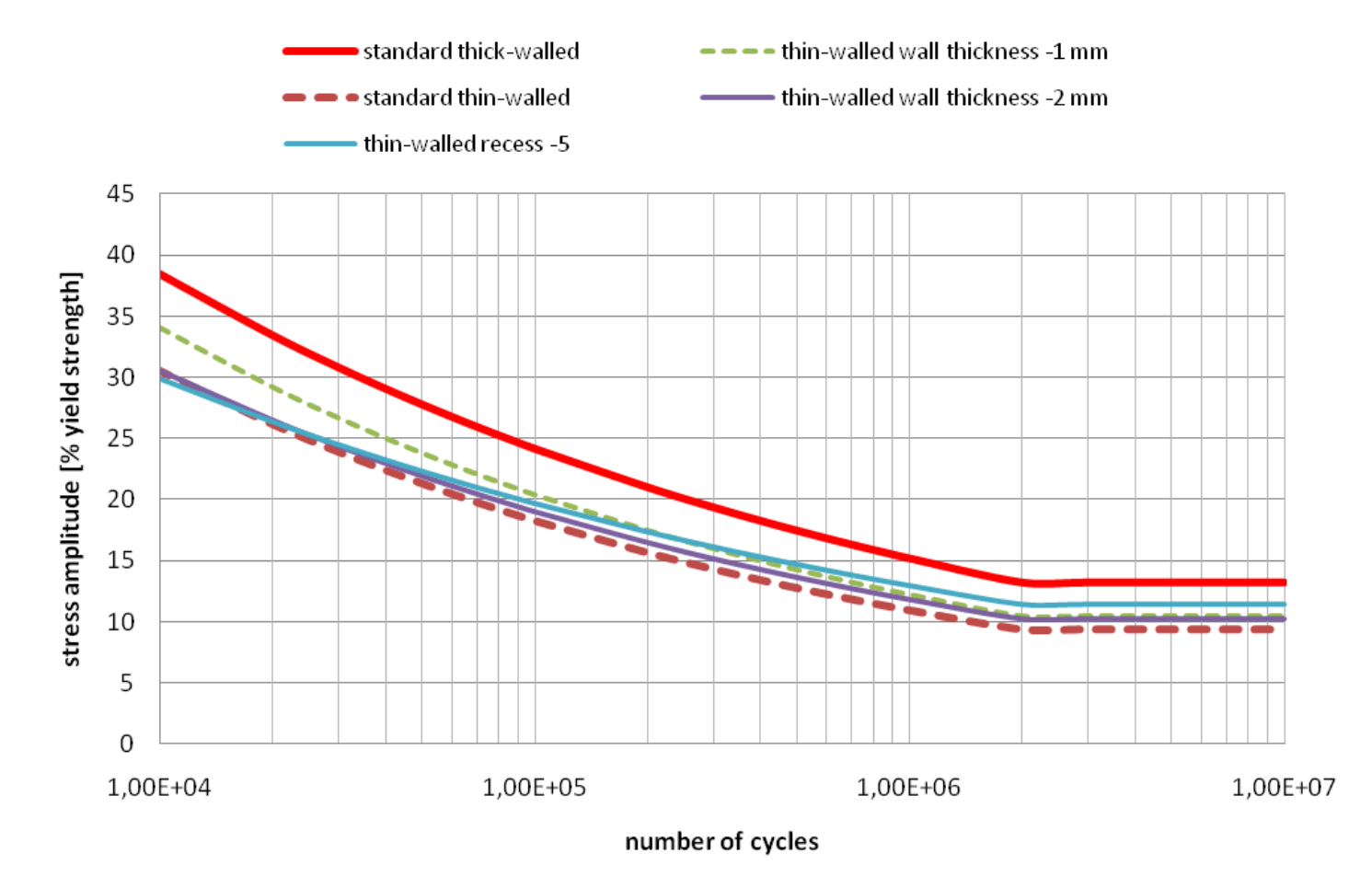

Figure 8: Comparison of S-N curves obtained for a standard thick-walled and for standard and premium thin-walled API Line Pipe couplings (1").

\section{SEALING CAPACITY OF AN API LINE PIPE CONNECTION}

\subsection{Test load envelope}

A connection's test load envelope is an indication of its sealing capacity. The envelope defines the boundaries of the combination of loads (axial force and internal pressure) within which the connection will maintain its structural and sealing integrity. Detailed procedures for testing are prescribed in the international standard ISO13679 [1]. The purpose of future research is to experimentally determine quadrant I and II of the test load envelope. Figure 9 shows an example of a test load envelope for a connection rated less than pipe body, which is the case for API line pipe.

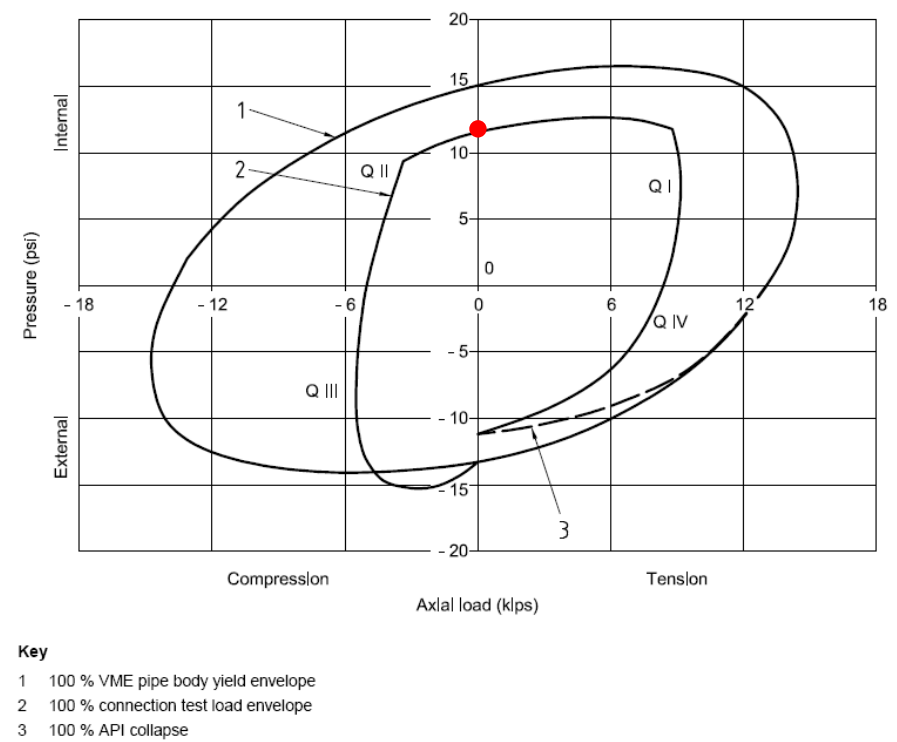

Figure 9: Test load envelope 
The red point on the test load envelope will be determined by just increasing internal pressure (without axial load) until leakage or loss of structural integrity occurs (possibly up to 600 bar [11]). Other well-chosen combinations of internal pressure and axial force will be determined by carrying out experiments on the setup described in the next section.

\subsection{Test setup}

The test setup can be divided into two main parts, related to internal pressure and axial load. First, there is a supply pump to establish a water pressure (up to 600 bar) in the pipe connection. The corresponding pressures will be registered by a digital pressure sensor. Secondly, the pipe connection is mounted in a servo-hydraulic testing machine by means of specially designed adaptor pieces suited for both tension and compression. Deformations of the test coupon will be measured by strain gauges and digital image correlation. A schematic section of the setup can be seen below in Figure 10.

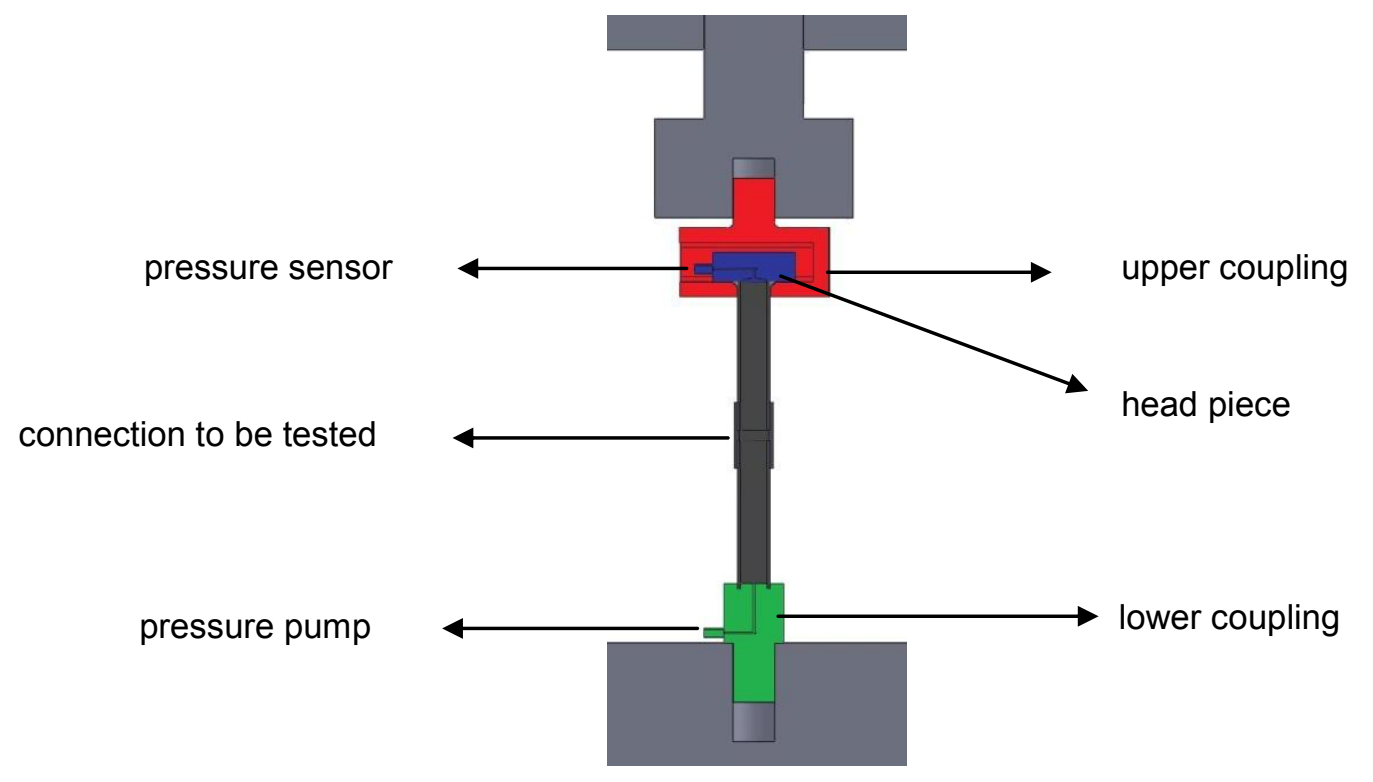

Figure 10: Section view leakage test setup

\section{CONCLUSIONS}

A 1" thick walled standard API Line Pipe coupling has a higher fatigue life as compared to standard and premium thinner walled connections. Numerical simulations have been performed in order to explain this experimental observation in a fundamental way. First evaluations of stress distribution over the connection and stress tri-axiality do not provide satisfying results. In the future the multi-axiality around the thread root will be studied in more detail using well-established multi-axial fatigue criteria.

A design for a leakage test setup is conceived and will be used to carry out experiments to determine the test load envelopes of different coupling configurations.

Further research should result in clear guidance on how to design threaded couplings with an optimal combination of sealing capacity and fatigue resistance. 
Sustainable Construction and Design 2011

\section{NOMENCLATURE}

API American Petroleum Institute

CAL Connection application level

LET Last Engaged Thread

$N_{f} \quad$ Fatigue life

$R \quad$ Load ratio

$\mathrm{R}_{\mathrm{v}} \quad$ Tri-axiality

$\Delta \sigma_{e q} \quad$ difference between the max. and min. von Mises equivalent stress during a load cycle

$\mathrm{S}_{\mathrm{a}} \quad$ Stress amplitude

TLP Tension Leg Platform

v Poisson's ratio

$\sigma_{v m} \quad$ Von Mises stress

$\sigma_{h} \quad$ Hydrostatic pressure 


\section{ACKNOWLEDGEMENTS}

The authors would like to acknowledge the support of the technical staff of Laboratory Soete.

\section{REFERENCES}

[1] ISO 13679, "Petroleum and gas industries - Procedures for testing tubing and casing connections," 2006.

[2] API Specification 5B, "Specifications for Threading, Gauging and Thread Inspection of Casing, Tubing and Line Pipe Threads (U.S. Customary Units)," Fourteenth ed, A. P. Institute, Ed., 1996.

[3] API Specification 5L, "Specifications for Line Pipe," Forty-second ed, A. P. Institute, Ed., 2000.

[4] J. De Pauw, "Experimenteel onderzoek op geschroefde buisverbindingen," in Mechanische constructie en productie Gent: Universiteit Gent, 2009.

[5] B. Meertens, "Experimenteel onderzoek naar het vermoeiingsgedrag van geschroefde buisverbindingen," in Mechanische constructie en productie Gent: Universiteit Gent, 2010.

[6] J. Van Wittenberghe, J. De Pauw, P. De Baets, W. De Waele, M.A. Wahab, G. De Roeck, "Experimental determination of the fatigue life of modified threaded pipe couplings," Procedia Engineering, vol. 2(1), pp. 1849-1858, 2010.

[7] M. Sugino, K. Nakamura and S. Yamaguchi,Sumitomo Metal Industries Ltd?, D. Daly, G. Briquet and E. Verger, Vallourec Mannesmann Oil \& Gas, " Development of an Innovative Highperformance Premium Threaded Connection for OCTG, Offshore Technology Conference, Houston, Texas, USA, 3-6 May, 2010

[8] J. Van Wittenberghe, J. De Pauw, P. De Baets, W. De Waele, " Fatigue life assessment of preloaded API Line Pipe threaded connections", Fatigue design, Cetim, Senlis, France, 25-26 November, 2009

[9] J. Van Wittenberghe, P. De Baets, W. De Waele, "Modelling of preloaded threaded pipe connections", Proc. of the 8th Nat. Congress on Theor. and App. Mechanics, 149-156, 2009.

[10] M.M. Abdel Wahab, A.I. Ashcroft, A.D. Crocombe, S.J. Shax, "Prediction of fatigue tresholds in adhesively bonded joints using damage mechanics and fracture mechanics, J. Adhesion Sci. Technol., 15(7), 763-781, 2001

[11] API 5C3 (ISO 10400), "Petroleum and natural gas industries - Formulae and calculation for casing, tubing, drill pipe and line pipe properties," 1993. 